Proc. of the XI Int. Conf. - Ion Implantation and other Applications of Ions and Electrons, Kazimierz Dolny 2016

\title{
Effect of High Energy Ion Implantation on the Structure and Mechanical Properties of Aluminium Alloys
}

\author{
V.M. AnishchiK ${ }^{a}$, N.I. POliak ${ }^{a, *}$, V.V. Ponaryadov ${ }^{a}$, M. OPIElaK $^{b}$ And O. Boiko ${ }^{c}$ \\ ${ }^{a}$ Belarusian State University, 4, Nezavisimosti Av., 220030, Minsk, Belarus \\ ${ }^{b}$ Institute of Transport, Combustion Engines and Ecology, Lublin University of Technology, \\ Nadbystrzycka 36, 20-618 Lublin, Poland \\ ${ }^{c}$ Department of Electrical Devices and High Voltage Technology, Lublin University of Technology, \\ Nadbystrzycka 36, 20-618 Lublin, Poland
}

\begin{abstract}
The effect of implantation of $\mathrm{Ne}^{+}, \mathrm{Kr}^{+}$, and $\mathrm{Bi}^{+}$ions over the energy range $26-710 \mathrm{MeV}$ on the structural-phase state and the mechanical properties of the aluminum-based alloys ( $\mathrm{Al}-\mathrm{Cu}, \mathrm{Al}-\mathrm{Cu}-\mathrm{Mg}, \mathrm{Al}-\mathrm{Cu}-\mathrm{Zn}, \mathrm{Al}-\mathrm{Mn}$ ) was studied. The revealed peculiarities of variations in the structure, phase composition, and mechanical properties of aluminum alloys are attributed to the electron deceleration of ions making the principal contribution to the formation of radiation defects which enhance the diffusion processes in the targets.
\end{abstract}

DOI: 10.12693/APhysPolA.132.291

PACS/topics: 61.80.Jh, 61.80.- $\mathrm{x}$

\section{Introduction}

High energy ion irradiation [1] is a promising area, useful and interesting application in radiation material physics and technology [2] and it plays an important role in radiation materials science [3].

Recently great interest has been observed in the use of high-energy ion beams $(E>1 \mathrm{MeV} /$ a.m.u.) for modification of the surface layers of metals and alloys. It is interesting that changes in the strength properties due to high-energy ion implantation (HEII) are similar to those in the case of medium-energy ion implantation. As for the greatest part of the trajectory of high energy ions, their energy losses are mainly due to inelastic interactions with the target atoms, the mechanisms governing the observed changes in the properties are still not clearly understood.

Of particular interest is ion implantation into precipitation hardening alloys because changes in their properties may result not only from the defect formation processes but also from the possible structural and phase transformations.

\section{Experimental}

Below the effect of implantation of $\mathrm{Ne}^{+}, \mathrm{Kr}^{+}$and $\mathrm{Bi}^{+}$ ions, over the energy range $26-710 \mathrm{MeV}$ when using small damage $\left(\approx 10^{-2}-10^{-4}\right.$ d.p.a. $)$, on the structure and mechanical properties of the aluminum-based alloys (Table I) is considered.

Alloy composition (wt\%).

TABLE I

\begin{tabular}{c|c|c|c|c|c|c|c|c}
\hline \hline Alloy & $\mathrm{Al}$ & $\mathrm{Cu}$ & $\mathrm{Mg}$ & $\mathrm{Mn}$ & $\mathrm{Zn}$ & $\mathrm{Si}$ & $\mathrm{Fe}$ & Group of alloys \\
\hline $\mathrm{Al}-\mathrm{Cu}$ & & 4 & - & - & - & - & - & \\
$\mathrm{Al}-\mathrm{Cu}-\mathrm{Zn}$ & basis & 3.5 & - & - & 2 & - & - & precipitation hardening \\
$\mathrm{Al}-\mathrm{Cu}-\mathrm{Mg}(\mathrm{D} 16)$ & metal & $3.8-4.9$ & $1.2-1.8$ & $0.3-0.9$ & - & $\leq 0.5$ & $\leq 0.5$ & \\
$\mathrm{Al}-\mathrm{Mn}$ & & $\leq 0.2$ & $\leq 0.5$ & $1.0-1.6$ & - & $\leq 0.6$ & $\leq 0.7$ & thermally nonhardening \\
\end{tabular}

Duralumin (D16) is a multicomponent and multiphase alloy. The process of its ageing involves the majority of dopants of copper and magnesium forming S- and $\theta$ phases $\left(\mathrm{CuMgAl}_{2}\right.$ and $\mathrm{CuAl}_{2}$, respectively) in the matrix. $\mathrm{Mg}_{2} \mathrm{Si}$ is also the strengthening phase. The observed effects were studied in detail and interpreted taking the binary alloy $\mathrm{Al}-4 \% \mathrm{Cu}$ as an illustration because its ageing is associated only with copper that forms $\theta$-phase in the process.

To study stability of the initial structural and phase state on high-energy ion implantation, the precipitation hardening alloys were examined at the different ageing stages: $\mathrm{D} 16$ and $\mathrm{Al}-3.5 \% \mathrm{Cu}-2 \% \mathrm{Zn}$ - at the zone and phase stages of ageing; the alloy $\mathrm{Al}-4 \mathrm{wt} \% \mathrm{Cu}$ - at the phase stage. The zone ageing is associated with the formation of the Guinier-Preston (GP) zones coherently coupled to the matrix, whereas the phase ageing - with metastable partially coherent precipitations and equilibrium incoherent precipitations. For comparison we studied the alloy $\mathrm{Al}-\mathrm{Mn}$, where manganese as a majority doping impurity forms the strengthening phase $(\mathrm{MnFe}) \mathrm{Al}_{6}$ insoluble under thermal conditions. 
Ion implantation of the alloys under study was performed at the JINR (Dubna, Russia) using the accelerator U-400. The sample temperature did not exceed $330 \mathrm{~K}$ during implantation. The structural properties of the alloys were investigated using the transmission electron microscopy (TEM) and X-ray diffraction (XRD). Mechanical properties were studied using hardness and wear testers.

\section{Results and discussion}

The effect of $\mathrm{Ne}^{+}$ion implantation $(E=26.7 \mathrm{MeV})$ on the precipitation hardening of D16 alloy (Fig. 1a-c) was studied at the fluences of $10^{15}$ and $2.5 \times 10^{15} \mathrm{~cm}^{-2}$. It was shown that, at the initial stage of implantation, microhardness of the alloys is lowered as a result of the block structure formation. An increase of the implantation fluence leads to hardening caused by the formation of fine-dispersed precipitations of S- and $\theta$-phases [4]. In the case of the alloy $\mathrm{Al}-\mathrm{Mn}$ (thermally nonhardening) (Fig. 1d-f), it was found that the radiation-stimulated hardening leads to much higher microhardness and to changes in the microstructure characteristic of plastically deformed metals [5].

As found, the evolution of the structural and phase states in the process of high-energy $\mathrm{Ne}^{+}$ions implantation of the studied aluminum alloys correlates well with changes in their microhardness.

It is demonstrated that the observed features of changes in the structure and properties of the aluminum alloys are caused by the electron deceleration of ions contributing to generation of the lattice defects, and their increased concentration facilitates the diffusion processes with dislocation climb and precipitation of the hardening phases. To elucidate a role of the initial structural and phase state of ageing alloys in changing of their properties under the effect of irradiation, the influence of high-energy implantation of krypton ions on microhardness of the D16 alloy was studied at different ageing stages $[6,7]$.

As a result of implantation of the $\mathrm{Kr}^{+}$ions $(E=$ $245 \mathrm{MeV}$, fluences: $5 \times 10^{12}-3 \times 10^{14} \mathrm{~cm}^{-2}$ ), lowering of microhardness as the fluence increases is observed for D16. However, in the alloy $\mathrm{Al}-\mathrm{Mn}$ implantation results in a considerable growth of microhardness [7].

For naturally aged samples a drastic decrease of microhardness with implantation fluences up to $10^{14} \mathrm{~cm}^{-2}$ was observed. Further increase of the fluences to $3 \times$ $10^{14} \mathrm{~cm}^{-2}$ leads to higher microhardness. The implantation effect on microhardness of the artificially aged samples is not so marked though a character of the fluence dependence is the same. Softening of D16 in this case can be associated with the radiation-induced processes of additional decomposition of a solid solution and with dissolution of the GP zones. Simultaneously with these processes, the radiation defects are formed contributing to hardening of the alloy. However, the data for changes in microhardness indicate no hardening due to high-energy ion implantation in the range of fluences under study. It
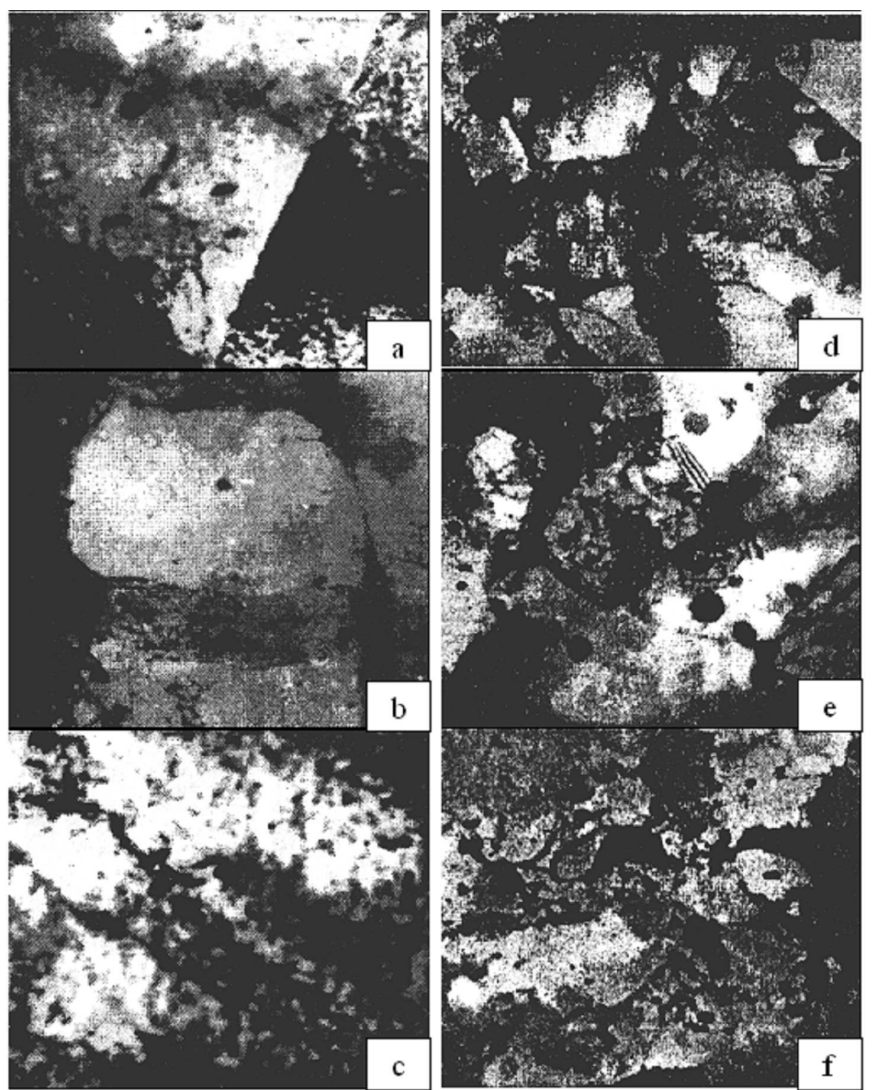

Fig. 1. Bright-field TEM images D16 (a)-(c) and AlMn (d)-(f) alloys: unimplanted $(\mathrm{a}, \mathrm{d})$ and implanted $10^{15}(\mathrm{~b}, \mathrm{e})$, and $2.5 \times 10^{15} \mathrm{~cm}^{-2}(\mathrm{c}, \mathrm{f})$.

can be concluded that at this implantation stage the softening processes associated with the structural and phase transformations are dominant.

In the case of overaged samples one can observe the microhardness growing with the implantation fluence possibly due to partial dissolution of the precipitates and to their increased dispersion with subsequent additional ageing of the alloy. Softening of the implanted quenched and aged alloys can be attributed to the radiationinduced processes of decomposition of a hard solution and dissolution of the metastable precipitates. Besides, microhardness may be significantly decreased by the dynamic return processes actively developing on implantation.

The correlation of physical broadening $\beta$ of the diffraction line 422 and the microhardness $H$ of the alloys was observed (Fig. 2).

Note that for the depths examined $(\approx 5 \mu \mathrm{m})$ inelastic losses in the energy of krypton ions are higher than elastic losses by a factor of $10^{3}$ and more. A level of the elastic energy losses comes to $0.21 \mathrm{eV} / \AA$, the displacement cross-section being $\sigma_{d}=1.57 \times 10^{-17} \mathrm{~cm}^{2}$. The damaging doses are $1.57 \times 10^{-4}$ and $4.7 \times 10^{-3}$ d.p.a. for the implantation fluences $10^{13}$ and $3 \times 10^{14} \mathrm{~cm}^{-2}$, respectively [8]. In the case of so low damaging doses the dissolution effect of the metastable phase $\theta^{\prime}$ can be due 
to the formation of collision chains with substitution in the collision cascade, as the number of substitutions is many times greater than that of displacement when the focusing conditions are met.

The atoms of copper released on dissolution of the $\theta^{\prime}$ phase precipitates lead to supersaturation of the matrix $\alpha$-solid solution at the interface with $\theta^{\prime}$-phase to result in precipitation of the metastable phase $S^{\prime}$. Realization of these processes necessitates sufficient numbers of mobile point defects.

Hardening of the alloy $\mathrm{Al}-\mathrm{Mn}$ is associated with accumulation of radiation defects in the implanted layer. They can retard the in-depth dislocation movement in the alloy and hence the surface layer is hardened.
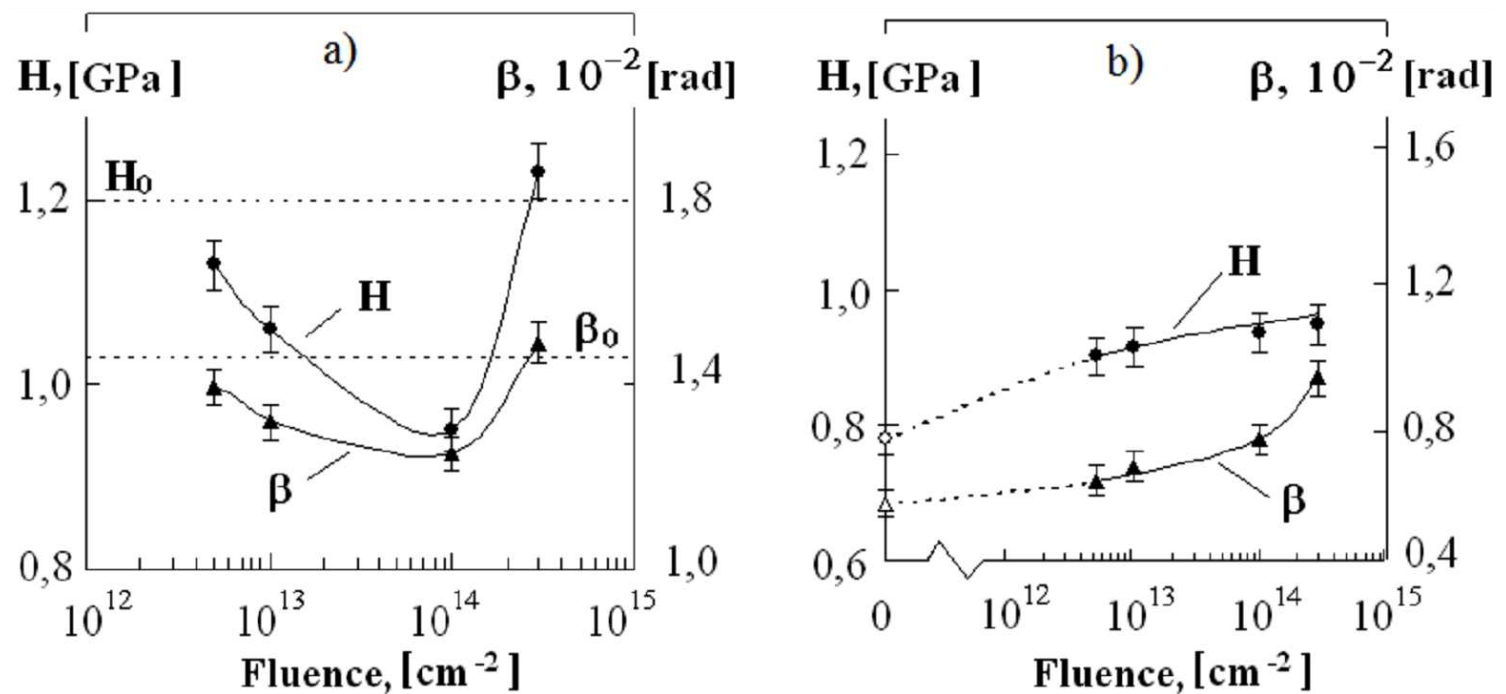

Fig. 2. Fluence dependence of the relative change in microhardness and physical broadening D16 alloy: naturally aged (a) and overaged samples (b).

Fine structure parameters of the alloys: $\sqrt{\overline{\varepsilon^{2}}}$ - the value of microstresses, $D$ - the size of coherent

TABLE II scattering regions, $\rho$ - effective density of dislocations, $\rho_{t}$ - true density of dislocations, $P-$ stress.

\begin{tabular}{c|c|c|c|c|c|c}
\hline \hline $\begin{array}{c}\text { System } \\
\text { (alloy) }\end{array}$ & $\begin{array}{c}\text { Fluence } \\
{\left[\mathrm{cm}^{-2}\right]}\end{array}$ & $\begin{array}{c}\sqrt{\overline{\varepsilon^{2}}} \\
{\left[10^{-3}\right]}\end{array}$ & $\begin{array}{c}D \\
{[\mu \mathrm{m}]}\end{array}$ & $\begin{array}{c}\rho \\
{\left[10^{10} \mathrm{~cm}^{-2}\right]}\end{array}$ & $\begin{array}{c}\rho_{t} \\
{\left[10^{10} \mathrm{~cm}^{-2}\right]}\end{array}$ & $\begin{array}{c}P \\
{[\mathrm{MPa}]}\end{array}$ \\
\hline D16 & unimplanted & 1.41 & - & 2.0 & - & 336 \\
(naturally & $10^{13}$ & 1.28 & - & 1.6 & - & 303 \\
aged) & $10^{14}$ & 1.02 & 0.15 & - & 0.09 & 1.2 \\
\hline \multirow{3}{*}{ Al-Mn } & unimplanted & 0.30 & - & 0.17 & - & 73 \\
& $10^{13}$ & 0.41 & - & 0.33 & - & 99 \\
& $10^{14}$ & 0.58 & - & & & 137
\end{tabular}

As demonstrated by the studies, a level of stresses (Table II) in the D16 alloy is lowered with the increased implantation fluence because of the radiation-induced processes of the additional solid-solution decomposition and due to dissolution of the GP zones leading to softening of the alloy, whereas a level of stresses in the alloy $\mathrm{Al}-$ $\mathrm{Mn}$ is growing significantly as a result of the accumulated radiation defects.

Like the two previous cases (D16 overaged alloy and thermally nonhardening $\mathrm{Al}-\mathrm{Mn}$ alloy) hardening effect at HEII is obtained for a binary alloy $\mathrm{Al}-4 \mathrm{wt} \% \mathrm{Cu}$. The initial structural and phase state of the alloy $\mathrm{Al}-4 \% \mathrm{Cu}$ corresponds to the stable phase $\theta$ in the form of spherical precipitates with the average size $d \approx 1 \mu \mathrm{m}$ and of lamellar precipitates with $d \approx 4-7 \mu \mathrm{m}$. Supposedly, the equilibrium spherical precipitates of $\mathrm{CuAl}_{2}$ precipitated directly from the $\alpha$-solid solution $(\alpha \rightarrow \theta)$, whereas the lamellar ones were formed by means of the transition $\left(\alpha \rightarrow \theta^{\prime} \rightarrow \theta\right)$. As shown in [9], implantation of $\mathrm{Kr}^{+}$ ions at the energy $245 \mathrm{MeV}$, up to the fluences $10^{13}$ and $10^{14} \mathrm{~cm}^{-2}$, into the alloy $\mathrm{Al}-4 \% \mathrm{Cu}$ with precipitations of the equilibrium phase $\theta$ leads to their partial dissolution (lowered density and volume fraction) to result in supersaturation of the matrix solid solution by copper atoms. A significant decrease in the intensity of the diffraction lines of $\theta$-phase (Fig. 3) attests to its partial dissolution during irradiation. The radiation-stimulated ageing processes are responsible for hardening of the alloy. It was found that the fluence dependence of microhardness for the alloy $\mathrm{Al}-3.5 \% \mathrm{Cu}-2 \% \mathrm{Zn}$ implanted with $\mathrm{Bi}^{+}$ions at 
the energy $710 \mathrm{MeV}$ is different for the artificial and natural ageing [10]. Implantation leads to lowering of the friction coefficient $\mu$ (Fig. 4).

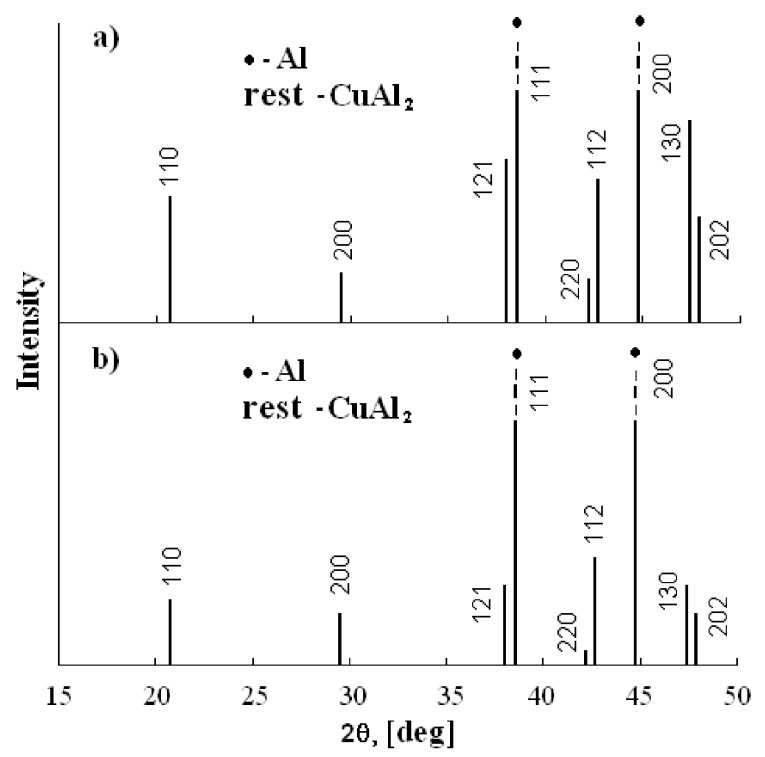

Fig. 3. X-ray diffraction patterns of alloy $\mathrm{Al}-4 \mathrm{wt} \% \mathrm{Cu}$ before (a) and after implantation $10^{14} \mathrm{~cm}^{-2}$ (b).

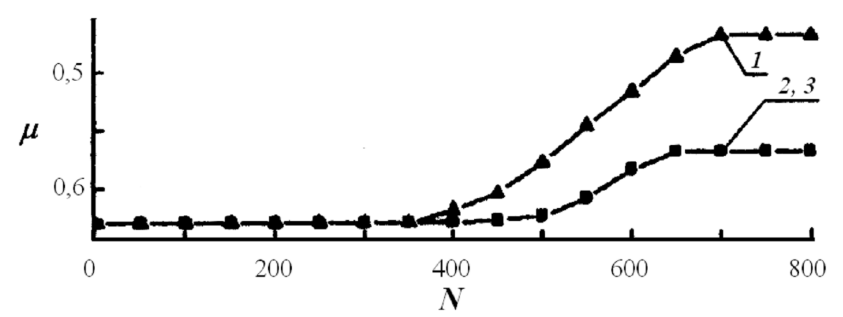

Fig. 4. The friction coefficient $\mu$ as a function of the number of cycles $N$ for naturally aged alloys Al$3.5 \% \mathrm{Cu}-2 \% \mathrm{Zn}$ before (1) and after implantation $5 \times$ $10^{12}(2)$ and $10^{13} \mathrm{~cm}^{-2}(3)$.

\section{Conclusions}

In this way in the case of precipitation hardening alloys and those not subjected to thermal hardening, their properties change differently due to different structural and phase states. The observed features in the changes of structure, phase composition, and properties of aluminum alloys are caused by the electron deceleration of ions contributing to the formation of radiation defects which accelerate diffusion processes in the targets.

\section{References}

[1] B. Slowinski, Acta Phys. Pol. A 96, 239 (1999).

[2] F.F. Komarov, A.F. Komarov, V. Pilko, V. Pilko, J. Eng. Phys. Thermophys. 86, 1481 (2013).

[3] I.M. Neklyudov, V.N. Voyevodin, in: Proc. Int. Conf. on Interaction of Radiation with Solids, Minsk, 2013,in Ref. [2], p. 127, (in Russian).

[4] V.M. Anishchik, S.I. Zhukova, L.A. Vasilyeva, Phys. Chem. Mater. Treatm. 6, 9 (1998), (in Russian).

[5] V.M. Anishchik, L.A. Vasilyeva, S.I. Zhukova, Phys. Chem. Mater. Treatm. 1, 5 (1998), (in Russian).

[6] V.M. Anishchik, S.I. Zhukova, N.I. Poliak, Phys. Chem. Mater. Treatm. 6, 9 (1999), (in Russian).

[7] V.M. Anishchik, S.I. Zhukova, N.I. Poliak, in: Proc. Int. Conf. on Interaction of Radiation with Solids, Minsk, 2001, p. 240, (in Russian).

[8] V.M. Anishchik, S.I. Zhukova, L.A. Vasilyeva, Phys. Chem. Mater. Treatm. 5, 37 (2001), (in Russian).

[9] S.I. Zhukova, N.I. Poliak, in: Proc. Int. Conf. on Interaction of Radiation with Solids, Minsk, 2003, p. 148, (in Russian).

[10] N.I. Poliak, Vestnik Belarussian State Univ. Ser. 1 2, 100 (2003), (in Russian). 